\title{
O exercício da cidadania na Constituição Federal de 1988 e na Lei no \\ 4717 de 1965: a legitimidade ativa na propositura da ação popular
}

\author{
Raquel Coca ${ }^{1}$
}

\begin{abstract}
Resumo
O objetivo deste trabalho é a discussão da legitimidade ativa na propositura da Ação Popular, por meio da análise do termo cidadania, cujo conteúdo foi percebido esvaziado, utilizado de maneira restrita, principalmente em época de eleições e em legislação infraconstitucional, especificamente na Lei no 4717 de 29 de junho de 1965, a qual regula a Ação Popular. A cidadania abraçada pela atual Constituição Brasileira teve seu conteúdo ampliado e não se restringe ao simples fato de possuir um título eleitoral, mas sim com o exercício da soberania popular, a democracia, a isonomia e a dignidade da pessoa humana.
\end{abstract}

Palavras Chave: Cidadania; Legitimidade ativa; Ação popular; Soberania popular.

\section{Introdução}

Em época de eleições muito se tem falado na expressão cidadania, pensando-a, muitas vezes, no sentido limitado de votar e ser votado, ou seja, como titular de direitos políticos. Essa interpretação restritiva tem respaldo na Lei no 4.717, de 29 de junho de 1965, que regula a Ação Popular e trata da legitimidade ativa em sua propositura, em seu Art.1요§ 3o: "A prova da cidadania, para ingresso em juízo, será feita com o título eleitoral ou com documento que a ele corresponda".

O conteúdo de cidadania em âmbito constitucional é mais amplo do que o simples fato de possuir um título eleitoral, para votar e ser votado. Ela não se restringe ao voto, o qual é apenas uma etapa do processo de cidadania (AGRA, 2002, p. 123). A atual Constituição amplia a cidadania, qualificando e valorizando os participantes da vida do Estado, e reconhecendo a pessoa humana como ser integrado na sociedade em que se vive, de acordo com José Afonso da Silva (2003, p. 344-345).

Cidadania é a participação efetiva no destino de um Estado por meios que façam com que os representantes do povo, eleitos para cargos políticos, cumpram as funções a eles atribuídas. A própria Constituição permite, por exemplo, o exercício da Ação Popular,

1 Aluna do 5ㅇa ano de Direito da Universidade Estadual de Londrina. 
uma garantia individual (Art. 50, inciso LXXIII) visando à tutela de interesses de toda a sociedade, os quais não devem ser submetidos a interesse particular. Cidadania engloba uma série de direitos, deveres e atitudes (...), a participação, ativa ou passiva na administração comum. Pressupõe, por exemplo, o pagamento de impostos, mas também a fiscalização de sua aplicação (PINSKY, 2002.p.18).

A Ação Popular constitui manifestação direta da soberania popular (SILVA, 2003 p. 460) e possui, de tal forma, respaldo no parágrafo único, do Art. 1ํ da Constituição de 1998: "Todo o poder emana do povo, que o exerce por meio de seus representantes eleitos ou diretamente". (grifos nossos). Assim, em vista da importância da referida garantia constitucional, o presente documento tem como objetivo a discussão a respeito da legitimidade ativa na propositura da Ação Popular, questão a seguir analisada.

\section{Cidadania: uma reflexão à luz da Constituição de 1998}

Muitos doutrinadores utilizam cidadania no mesmo sentido de nacionalidade (Art. 12 da Constituição Federal) e de direitos políticos (Art. 14), com respaldo no § 3ㅇ do Art. 1으 da Lei $n$ ㅇ 4717/65, já supradito. No entanto, a Constituição estabelece como Fundamentos da República Federativa do Brasil, além de outros elencados no Art. 1으, os seguintes: a cidadania; a dignidade da pessoa humana, devendo-se lembrar também o princípio da isonomia, presente no caput do Art. 5ำ, além de, a seguir, a legitimação para a propositura da Ação Popular, garantia contida no inciso LXXIII do mesmo dispositivo constitucional:

Art. 50. Todos são iguais perante a lei, sem distinção de qualquer natureza, garantindo-se aos brasileiros $\mathrm{e}$ aos estrangeiros residentes no País, a inviolabilidade do direito à vida, à liberdade, à igualdade, à segurança e à propriedade, nos termos seguintes:

(...)

LXXIII: qualquer cidadão é parte legítima para propor ação popular

(...). (grifos nossos).

Percebe-se ser uma norma de eficácia limitada, que necessita de norma integradora para deixar definitivamente afirmado quem é cidadão para efeito do exercício da referida garantia. 


\section{A questão da legitimidade ativa na propositura da ação popular}

A Lei $n$ ㅇ 4717/65, em seu $\S 3$ 을 do Art. 1으, mostra-se incompleta e lacunosa para definir a abrangência da expressão protegida pela atual Constituição Federal, pois se aquela afirma ser a prova da cidadania feita por meio de título eleitoral, ou documento que a ele corresponda, afirma ser cidadão somente quem possuí o título ou o protocolo de solicitação do mesmo. Ou haveria outro documento a ele correspondente?

Essa restrição acanha a Ação Popular, para controle da lesividade e da ilegalidade que qualquer agente público tenha praticado ou possa praticar ao patrimônio público, e também para controle da moralidade administrativa.

De acordo com Júlio Sérgio Monte Alegre (apud MANCUSO, 2001. p. 146), por localizar-se no Art. 5o da Constituição, justificaria a ilação de que ela (Ação Popular) "deveria ser estendida a quem aqui residisse e pagasse seus impostos, o que incluiria os estrangeiros".

Lúcia Valle Figueiredo (2004, p. 418-419) sugere a extensão da legitimidade "às associações de classe, à Ordem dos Advogados do Brasil, que se têm manifestado tão atuante ao longo desses anos".

Há, ainda, a Súmula 365 do STF: “Pessoa Jurídica não tem legitimidade para propor Ação Popular", a qual data de 16 de dezembro de 1963, e, portanto, relaciona-se com a Constituição de 1946. Já a Constituição de 1988 legitima para tal exercício a pessoa humana e não se restringe aos conceitos de pessoa física e pessoa jurídica, que são terminologias empregadas pelo Fisco.

“Os tribunais não devem esperar a alteração do Texto Constitucional, mas interpretá-lo, atendendo aos fins sociais (políticos) a que ele se dirige e às exigências do bemcomum, de modo que (...) todas as instituições públicas ou privadas possam, diante do ato lesivo ao patrimônio público ou equiparado, propor ação popular destinada à invalidação daquela". (apud PACHECO, 2002. p. 568).

Acorda-se, assim, com a significação da expressão cidadania, a qual “(...) parece não se resumir à posse de direitos políticos, mas em acepção diversa, parece galgar significado mais abrangente, nucleado na idéia, expressa por Hanna Arendt, do direito a ter direitos. Segue-se, nesse passo, que a idéia de cidadania vem intimamente entrelaçada com a de dignidade da pessoa humana" (ARAÚJO; NUNES JR., 2004, p. 79). 
É importante lembrar que ao tratar da legitimidade ativa na propositura da Ação Popular, não se quer enfatizar apenas o direito da pessoa humana, ou seja, daqueles a quem abrange a cidadania, mas também o dever. Primeiro porque o inciso LXXIII, do Art. 50 da Constituição localiza-se no Capítulo I "Dos Direitos e Deveres Individuais e Coletivos". Depois, e não menos importante, é que os deveres são sempre conexos com os direitos: o direito de impetrar a Ação Popular relaciona-se com o dever de coibir a lesividade proveniente da imoralidade administrativa.

Poderia existir quem quisesse contestar esta assertiva, alegando que o não cumprimento do citado "dever" nenhuma sanção haveria de trazer àquele que não o cumprisse. Ledo engano. Como se trata da cura da "res publica", através de um dos remédios constitucionais, no caso a ação popular (...), o seu não-exercício, assentado numa possível omissão ou acomodação, não só traria prejuízo ao omisso ou ao acomodado, como também a todos os componentes da sociedade. (CARNEIRO, 1995. p. 228).

Segundo Rafael Bielsa (apud CARNEIRO, 1995, p. 228): "o sentido constitucional deve estar acompanhado de um estado de espírito alerta, que não ceda um instante à ilegalidade, à negociata e à intimidação. É, pois, educação e mentalidade de um povo. Os fatores que se opõem ao desenvolvimento desse sentido são, principalmente, de duas espécies: a covardia, ignorância e ceticismo do povo, por um lado; o egoísmo e utilitarismo amoral das classes dirigentes, por outro". E termina, "As violações da Constituição somente o preocupam quando se trata da propriedade, de seus interesses. Nesse caso, a ação popular tem um papel importante, a tal ponto que pode ser providencial (grifos nossos)."

Cabe frisar a relação entre cidadania e democracia. Esse regime não se realiza sem a cidadania ativa, ou seja, a democracia se concretiza por meio da soberania popular, decorrente da consciência plena da cidadania pelos indivíduos integrantes de um Estado. (NOGUEIRA DA SILVA, 2003 p. 71). É necessária a participação do povo nas decisões políticas, sem a qual as instituições democráticas não podem ser aprimoradas.

\section{Conclusão}

De acordo com os fundamentos da República, a dignidade da pessoa humana e a cidadania, e com o princípio constitucional da isonomia, verifica-se a necessidade de revisão do Art. 1ㅇ § 3o da Lei 4717/65, e enquanto isso não ocorrer, obedecer-se-ão às técnicas de 
interpretação, aplicando-se a dicção constitucional para a propositura de tão importante garantia de ordem política, e não a lei mencionada para fins de ajuizamento da Ação Popular. Por último, frisa-se a necessidade de rever o sentido da expressão cidadania, tão simplista e equivocadamente ensinada para a população mais simples e humilde da sociedade brasileira, sentido esse incompatível com o Estado Democrático de Direito que se quer (re)construir.

\section{Referências}

AGRA, Walber de Moura. Manual de Direito Constitucional. São Paulo: Revista dos Tribunais, 2002.

ARAUJO, Luiz Alberto David;NUNES JÙNIOR, Vidal Serrano. Curso de Direito Constitucional. São Paulo: Saraiva, 2004.

CARNEIRO, Ruy de Jesus Marçal. Ação Popular: um direito-dever do cidadão e a moralidade administrativa. Cadernos de Direito Constitucional e Ciência Política, São Paulo, v. 3, n. 13, p. 219-233, out./dez. 1995.

CARVALHO, Kildare Gonçalves. Direito Constitucional Didático. 9. ed. Belo Horizonte: Del Rey, 2003.

FIGUEIREDO, Lúcia Valle. Curso de Direito Administrativo. São Paulo: Malheiros, 2004.

MANCUSO, Rodolfo de Camargo. Ação Popular. São Paulo: Revista dos Tribunais, 2001.

PACHECO, José da Silva. Mandado de Segurança e outras ações constitucionais típicas. São Paulo: Revista Tribunais, 2002.

PINSKY, Jaime. Cidadania e Educação. São Paulo: Contexto, 2002;

SILVA, Paulo Napoleão Nogueira da. Curso de Direito Constitucional. Rio de Janeiro: Forense, 2003.

SILVA, José Afonso da. Curso de Direito Constitucional. 22. ed. São Paulo: Malheiros, 2003. 
